\title{
Pneumatose intestinal em mulher com anorexia nervosa
}

\author{
Intestinal pneumatosis in woman with anorexia nervosa
}

\author{
Ana L Silva, Carolina Ourique, Paula Dias, Fernando Friões \\ Serviço de Medicina Interna, Centro Hospitalar de São João, Porto (Portugal)
}

\begin{abstract}
Resumen
A pneumatose intestinal é a presença de gás na parede intestinal. Pode anunciar uma catástrofe intra-abdominal ou ser simplesmente um achado em doentes assintomáticos. Apresentamos o caso de uma mulher de 20 anos, com anorexia nervosa e quadro de desnutrição grave, com pneumatose intestinal como achado imagiológico assintomático.

Palabras clave: Pneumatosis Intestinal. Anorexia nerviosa

Keywords: Pneumatosis Intestinalis. Anorexia nervosa
\end{abstract}

\section{Introdução}

A pneumatose intestinal é uma entidade rara e deve ser interpretada consoante 0 contexto clínico ${ }^{1}$ : pode anunciar uma catástrofe intra-abdominal ou ser apenas um achado em doentes assintomáticos. A etiologia não está esclarecida, e parece ser multifactorial. Estão propostas várias teorias, das quais destacamos duas: a teoria mecânica, segundo a qual 0 gás passa para a parede intestinal por um mecanismo de pressão aumentada, seja intraluminal, como no caso de uma oclusão intestinal, e passando através da mucosa com soluções de continuidade, ou intratorácica, como em doentes com enfisema pulmonar, passando através da serosa, vindo do mediastino e seguindo o curso dos vasos mesentéricos; e a teoria bacteriana, que sugere 0 acesso de bactérias formadoras de gás à parede intestinal através de lesões na mucosa intestinal ou do aumento da permeabilidade da mesma. ${ }^{2,3}$

\section{Caso clínico}

Apresentamos o caso de uma mulher de 20 anos, com anorexia nervosa grave. Admitida em Unidade de Cuidados Intermédios por quadro de desnutrição grave (índice Massa Corporal 11,5kg/ $\mathrm{m}^{2}$ ), com hipoglicemia, pancitopenia, múltiplos distúrbios iónicos e elevação de enzimas hepáticas e pancreáticas. Documentada pneumatose intestinal em radiografia (Imagem A), confirmada em tomografia computorizada abdominal (Imagem B). A doente não apresentava qualquer queixa abdominal e 0 exame abdominal era inocente. Manteve vigilância clínica, com resolução da pneumatose em reavaliação imagiológica.

\section{Discussão}

A pneumatose intestinal pode surgir em inúmeros contextos clínicos, nomeadamente em adultos com asma, doença pulmonar obstrutiva crónica ou sob ventilação mecânica, após procedimentos endoscópicos ou em doentes com algum tipo de imunossupressão; pode também surgir associada a quadro intra-abdominais graves, como infecções intra-abdominais, colite isquémica ou perfuração do tracto gastro-intestinal ${ }^{1}$. Nem sempre representa indicação cirúrgica e
Imagem A. A radiografia revela pneumatose intestinal no cólon ascendente caracterizada por imagens radiolucentes curvilíneas visíveis na parede das ansas intestinais (setas).

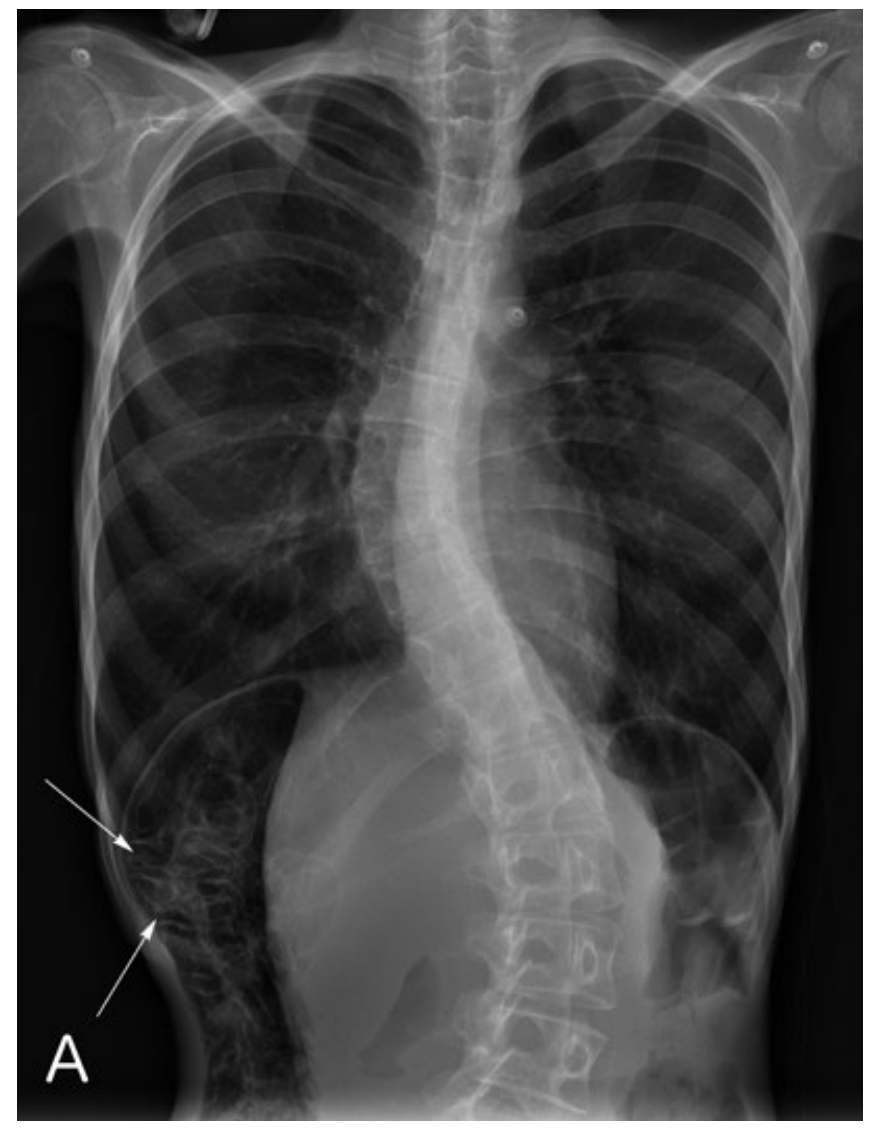


Imagem B. A TC abdominal (janela pulmonar) confirma a presença de ar na parede do cólon ascendente (setas).

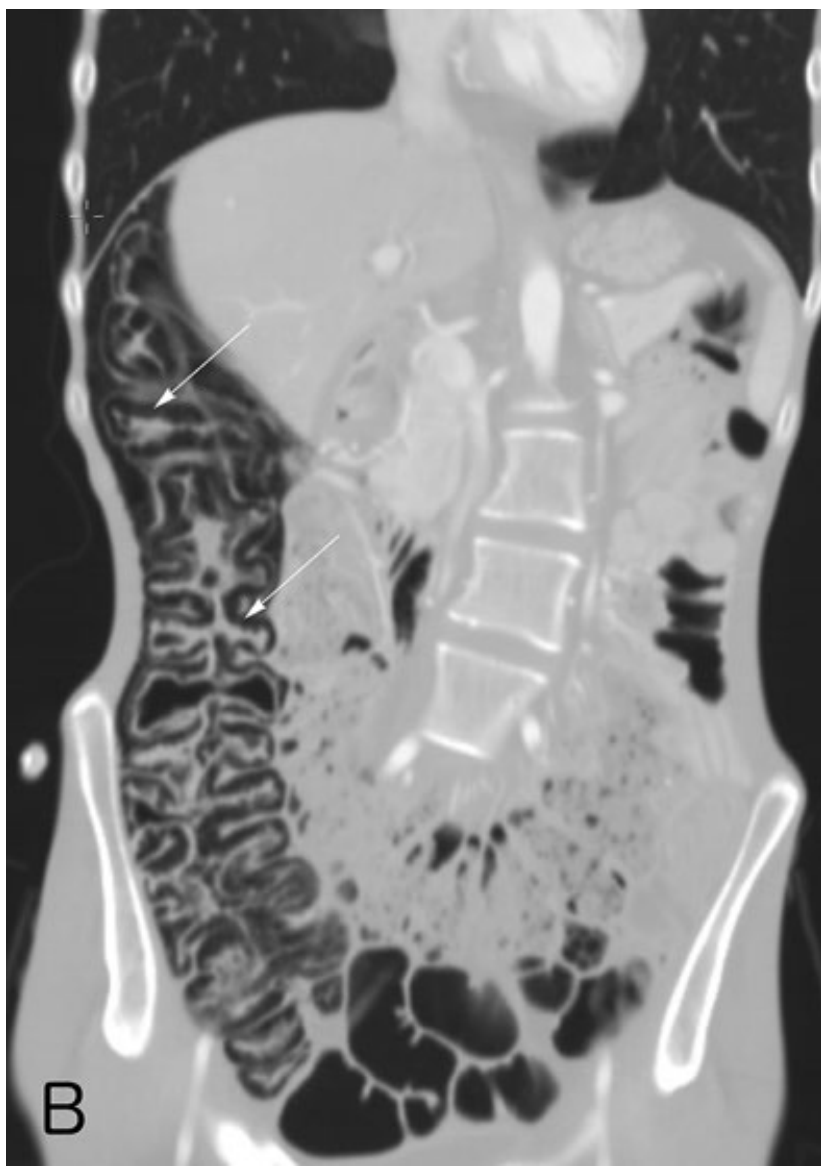

surge cada vez mais como um achado imagiológico acidental em doentes assintomáticos ${ }^{4}$. No caso descrito, avança-se a hipótese de a anorexia nervosa e a desnutrição graves, com consequente imunossupressão e aumento da permeabilidade da mucosa, a par com 0 aumento da pressão intratorácica relacionada com 0 comportamento purgativo recorrente, estarem na origem da pneumatose intestinal, encontrando-se na literatura casos semelhantes ${ }^{5-7}$.

\section{Bibliografía}

1. Heng Y, Schuffler MD, Haggitt RC, Rohrmann CA. Pneumatosis intestinalis: a review. Am J Gastroenterol 1995; 90:1747.

2. Galandiuk S, Fazio WW. Pneumatosis cystoidis intestinalis. A review of the literature Dis Colon Rectum 1986 May;29(5):358-63.

3. Ho LM, Paulson EK, Thompson WM. Pneumatosis intestinalis in the adult: benign to life-threatening causes. AJR Am J Roentgenol 2007 Jun;188(6):1604-13.

4. Nathan $\mathrm{H}$, Singhal $\mathrm{S}$, Cameron JL. Benign pneumatosis intestinalis in the setting of celiac disease. J Gastrointest Surg 2006 Jun;10(6):890-4

5. García X, Soler L, Amer M, Camacho J, Arnalich F. Twenty one year old male with cachexia and presence of abundant amount of intraabdominal gas. Rev Clin Esp 2006 Jul-Aug;206(7):355-6

6. Arenal JJ, Said A, Tinoco C, Mato MJ, Otero M, Guerro JÁ. Colonic pneumatosis intestinalis in a patient with neutropenia secondary to anorexia nervosa. Rev Esp Enferm Dig. 2011 Jul;103(7):391-2

7. Dzirlo L, Haunold I, Lung S, Buchinger E, Müller-Knespel EM, Weiss P. Pneumatosis intestinalis in anorexia nervosa: a case report. Z Gastroenterol. 2013 Nov;51(11):1265-8.

\section{Normas de publicación Galicia Clínica}

Galicia Clínica es la revista oficial de la Sociedad Gallega de Medicina Interna (SOGAMI). Se publican 4 números al año, simultáneamente en papel y en www.galiciaclinica. info, incluyéndose en el segundo de ellos las comunicaciones enviadas a la correspondiente Reunión Ordinaria de la SOGAMI.

\begin{abstract}
GALICIA CLINICA evaluará para su publicación trabajos médicos relacionados preferentemente con la Medicina Interna y sus subespecialidades, y/o con problemas médicos prevalentes en la Comunidad Autónoma de Galicia.

Se admitirán para evaluación trabajos en castellano, gallego, inglés y portugués.

Para el envio de originales se ha habilitado un formulario en la pagina web www.galiciaclinica.info. El sistema confirmará entrega y permitirá consultar el estado del manuscrito. No se aceptarán originales enviados por otros métodos.

El comitée editorial, eventualmente con la ayuda de revisores externos, evaluará los trabajos enviados decidiendo si procerle su publicación, si es necesario realizar correcciones o si se desestima la publicación. Una vez aceptado, se enviarán a autor las pruebas de imprenta para la corrección de posibles erratas.

Los trabajos reunirán los requisitos de uniformidad habituales en revistas biomédicas. Dichos requisitos se pueden consultar en "Uniform Requirements for Manuscripts Submitted to Biomedical Journals: Writing and Editing for Biomedica Publication, Updated April 2010", disponible en http://www.icmje.org. Se recomienda encarecidamente leer en especia la sección "Preparing a Manuscript for Submission to a Biomedical Journal" (http://mww.icmje.org/manuscript_1prepare. html) y seguir fielmente sus indicaciones a la hora de redactar el trabajo a enviar.

Se recomienda el empleo de los programas más habituales de edición de texto (E..., Word) tanto para el texto como para as tablas.

Dado que la mayoría de las páginas se imprimen en blanco y negro, se aconseja evitar en tablas y figuras en la medida de lo posible el uso de colores o tramas que no tengan el adecuado contraste para su identificación.

Las figuras o imágenes se enviarán en archivo aparte, como archivo de imagen (jpeg o similar) o como PDF con una resolución de 300 ppp. a tamaño de impresión definitivo.
\end{abstract}

La revista presenta las siguientes secciones:

Editoriales

Habitualmente encargados por la dirección de la revista. Su extensión máxima será de 8 páginas de 30 lineas y se admitirí una figura 0 una tabla y quince citas bibliográficas.

El número máximo de firmantes será de dos.

Originales

Trabajos de investigación sobre cualquier aspecto médico. La estructura general de los trabajos será la tradicional: Titulo: en el idioma original y en ingless, Resumen y Abstract en ingles, Palabras clave y Key words (que deben corresponder a los medical subjets headings -MESH- del Index Medicus), Introducción, Material y métodos, Resultados, Discusión, Bibliografí La extensión máxima recomendada del texto es de 20 páginas de 30 líneas, a las que se podrán añadir 5 figuras y 5 tablas, y un máximo de 30 citas bibliográficas. El número máximo de firmantes será de ocho.

Originales breves

Trabajos de investigación que por sus características no precisan un mayor espacio. Estructura similar a la de los originaSu extensión máxima será de 10 páginas de 30 lineas, 3 figuras, 3 tablas y 20 citas bibliográficas. El número máximo de firmantes será de seis.
Revisiones

Habitualmente encargadas por la dirección de la revista. La extensión máxima recomendada del texto es de 30 páginas de 30 lineas, a las que se podrán añadir 6 figuras y 6 tablas, y un máximo de 50 citas bibliográficas.

El número máximo de firmantes será de tres.

Preguntas clínicas

En esta sección se tratará de responder de forma concreta y sucinta a preguntas clinicas concretas que, bien han motivado una controversia, o cuestionan actitudes arraigadas en la práctica diaria. La extensión máxima será de 6 páginas de 30 lineas, dos figuras y dos tablas y 15 citas bibliográficas.

El número máximo de firmantes será de dos.

Notas clínicas

Descripción de casos clínicos de excepcional interés. Constarán de una breve introducción, caso clínico, y discusión correspondiente. Su extensión máxima será de 6 páginas, 2 figuras y dos tablas y 15 citas bibliográficas.

El número máximo de firmantes será de cuatro.

Cartas al director

Comentarios opiniones u observaciones sobre los diversos trabajos publicados con anterioridad en la revista La extensión máxima será de 4 páginas de 30 líneas y se admitirá una figura 0 una tabla y diez citas bibliográficas.

El número máximo de firmantes será de dos.

Imágenes médicas

Imágenes curiosas, insólitas o demostrativas. Se acompañarán con un texto breve, como máximo 1 página de 30 lineas, en el que se explique el caso clíico, con una breve discusión acerca de la importancia de la imagen.

El número máximo de firmantes será de dos.

Resúmenes de Tesis doctorales

Elaborados por rel autor, describirán el trabajo realizado: su extensión máxima será de 2 páginas de 30 lineas. Debe incluirse un apéndice con los datos correspondientes a Universidad, departamento, director de la tesis y fecha de presentación. Otros

La dirección de la revista considerará para su publicación cualquier articulo relacionado con la medicina en cualquier aspecto, aunque no se incluya exactamente dentro de los supuestos anteriores. En este caso se recomienda antes de su envio contactar con la dirección para acordar las caracteristicas del mismo.

En el caso de que los trabajos enviados incluyan imágenes, figuras, tablas o textos sometidos a copyright, será responsabilidad de los autores la obtención de los permisos necesarios para su publicación.

Todas las opiniones o afirmaciones expresadas en los articulos corresponden a los autores de los mismos. Tanto el comité editorial como la SOGAMI declinan cualquier responsabilidad a este respecto.

Los trabajos publicados serán propiedad de GALCIA CLINCA, cediendo los autores todos los derechos a la misma. 